\title{
Erratum to: Application of the effective formula of growth functional to quantitative description of growth of plant cells
}

\author{
Paweł Zajdel $^{1} \cdot$ Mariusz Pietruszka $^{2} \cdot$ Aleksandra Haduch-Sendecka $^{2}$
}

Published online: 25 October 2016

(C) Franciszek Górski Institute of Plant Physiology, Polish Academy of Sciences, Kraków 2016

\section{Erratum to: Acta Physiol Plant (2016) 38:216 \\ DOI 10.1007/s11738-016-2233-4}

In the "Conclusions" section an accidental erroneous occurrence of "influx rate" should be replaced by "efflux rate". The corrected sentence reads:

"Recently, the presented approach was successfully applied to quantitatively describe effective diffusion rates and correlations between growth and proton efflux rates in Zea mays L. (Pietruszka and Haduch-Sendecka 2016)."

The online version of the original article can be found under doi:10.1007/s11738-016-2233-4.

Mariusz Pietruszka

mariusz.pietruszka@us.edu.pl

1 Institute of Physics, University of Silesia, 40007 Katowice, Poland

2 Faculty of Biology and Environment Protection, University of Silesia, 40032 Katowice, Poland 